\section{Performance and Resistance to Phytophthora Crown and Root Rot in Squash Lines}

\author{
Kyle E. LaPlant ${ }^{1}$, Gregory Vogel ${ }^{1,2}$, Ella Reeves ${ }^{2}$, \\ Christine D. Smart ${ }^{2}$, and Michael Mazourek ${ }^{1}$
}

AdDitional INDEX wORDs. Cucurbita pepo, disease resistance, oomycete, Phytophthora capsici, pumpkin

Summary. Phytophthora crown and root rot, caused by the oomycete pathogen Phytophthora capsici, is a devastating disease of squash and pumpkin (Cucurbita pepo). No currently available cultivars provide complete resistance to this disease. Three newly developed squash lines and four hybrids were evaluated in greenhouse and field experiments for their resistance to phytophthora crown and root rot as well as for their horticultural performance. The three newly developed lines ranked among the most resistant entries included in 2 years of field trials. In addition, in a separate greenhouse experiment, one of the lines was shown to display the least severe disease symptoms among a group of accessions previously reported to possess partial resistance to phytophthora crown and root. Furthermore, the resistance was observed to be robust to several isolates of $P$. capsici. However, the phytophthoraresistant lines had reduced yield relative to standard squash cultivars. These lines are useful for continued breeding efforts toward a phytophthora crown and root rotresistant cultivar.

S quash and pumpkin (Cucurbita pepo) are important crops for vegetable growers in the United States. In $2018, \approx 100,000$ acres of squash and pumpkin were grown with a value of $\$ 350$ million [U.S. Department of Agriculture (USDA), 2019]. These crops are cultivated for food as immature fruit (summer squash) and mature fruit (winter squash and processing pumpkins),

Received for publication 25 Apr. 2020. Accepted for publication 9 Aug. 2020

Published online 2 September 2020

${ }^{1}$ Plant Breeding and Genetics Section, School of Integrative Plant Science, Cornell University, Ithaca, NY 14853

${ }^{2}$ Plant Pathology and Plant-Microbe Biology Section, School of Integrative Plant Science, Cornell University, Geneva, NY 14456

K.E.L. was supported by a Calvin Knoyes Keeney graduate fellowship from Cornell's College of Delta and Life Sciences. E.R. was supported by USDA National Institute of Food and Agriculture grant 2016-67032-25009. G.V. and supplies for the work were supported by New York State Department of Agriculture and Markets grants C00024GG and C00136GG to C.D.S. and M.M.

We thank Jessica Leonard for her help with screening the U.S. Department of Agriculture (USDA) Plant Introduction collection to identify potential sources for phytophthora crown and root rot resistance.

The authors declare they have no conflict of interest. M.M. is a co-founder of Row 7 Seeds, but has no financial stake in the company.

M.M. is the corresponding author. E-mail: mm284@ cornell.edu.

This is an open access article distributed under the CC BY-NC-ND license (https://creativecommons.org/ licenses/by-nc-nd/4.0/).

https://doi.org/10.21273/HORTTECH04636-20 and they are also grown for fall decorations, such as jack-o'-lanterns and gourds (Paris, 2016).

Phytophthora crown and root rot, caused by the oomycete pathogen Phytophthora capsici, is a severe disease affecting squash and pumpkin. Originally described in 1922 after being identified on pepper [Capsicum annum (Leonian, 1922)], it was first reported on cucurbits (Cucurbitaceae) in 1937 (Kreutzer, 1937). Now known to infect a wide range of species, other hosts of P. capsici include all cucurbits, eggplant (Solanum melongena), tomato (Solanum lycopersicum), and snap bean (Phaseolus vulgaris) (Lamour et al., 2012; Tian and Babadoost, 2004). Phytophthora capsici is widespread in cucurbit production regions of the United States, and the incidence of disease has increased in recent years
(Hausbeck and Lamour, 2004; Meyer and Hausbeck, 2012, 2013b). Squash and pumpkin plants can be affected by $P$. capsici during various growth stages, resulting in seedling damping off, vine and foliar blight, and fruit rot (Babadoost, 2004; Babadoost and Islam, 2003; Hausbeck and Lamour, 2004; Krasnow et al., 2014; Meyer and Hausbeck, 2013a).

The presence of both mating types of $P$. capsici in a field results in sexual reproduction and the generation of thick-walled oospores capable of surviving in the soil for many years (Babadoost, 2004; Carlson et al., 2017). These oospores often serve as the primary source of inoculum, germinating after a period of dormancy and initiating the asexual cycle (Granke et al., 2012; Hausbeck and Lamour, 2004). During favorable conditions, asexual reproduction by $P$. capsici results in rapid proliferation of the pathogen, often leading to complete yield loss during severe outbreaks (Babadoost, 2000, 2004; McGrath, 2017). Runoff from infected fields may contaminate surface water sources, such as creeks, rivers, and ponds, which then transport the pathogen long distances and lead to new epidemics (Hausbeck and Lamour, 2004; Jones et al., 2014).

Control of phytophthora crown and root rot remains a challenge for squash and pumpkin producers. Total eradication of the pathogen from an infected field is typically impossible, which has forced growers to abandon entire fields in some cases (Babadoost, 2004). Fungicides can be effective in limiting disease in squash and pumpkin, although severe crop loss can still occur despite their use when environmental conditions are favorable (Granke et al., 2012). Furthermore, insensitivity to some of

\begin{tabular}{llll}
\hline $\begin{array}{l}\text { Units } \\
\begin{array}{l}\text { To convert U.S. to SI, } \\
\text { multiply by }\end{array}\end{array}$ & U.S. unit & SI unit & $\begin{array}{l}\text { To convert SI to U.S., } \\
\text { multiply by }\end{array}$ \\
\hline 0.4047 & $\mathrm{acre}(\mathrm{s})$ & $\mathrm{ha}$ & $2.471 \mathrm{l}$ \\
29.5735 & $\mathrm{fl} \mathrm{oz}$ & $\mathrm{mL}$ & 0.0338 \\
0.3048 & $\mathrm{ft}$ & $\mathrm{m}$ & 3.2808 \\
3.7854 & $\mathrm{gal}$ & $\mathrm{L}$ & 0.2642 \\
2.54 & inch $(\mathrm{es})$ & $\mathrm{cm}$ & 0.3937 \\
0.4536 & $\mathrm{lb}$ & $\mathrm{kg}$ & 2.2046 \\
1.1209 & $\mathrm{lb} / \mathrm{acre}$ & $\mathrm{kg} \cdot \mathrm{ha}^{-1}$ & 0.8922 \\
0.1198 & $\mathrm{lb} / \mathrm{gal}$ & $\mathrm{kg} \cdot \mathrm{L}^{-1}$ & 8.3454 \\
0.0254 & $\mathrm{mil}(\mathrm{s})$ & $\mathrm{mm}$ & 39.3701 \\
28.3495 & $\mathrm{Oz}$ & $\mathrm{g}$ & 0.0353 \\
$\left({ }^{\circ} \mathrm{F}-32\right) \div 1.8$ & ${ }^{\circ} \mathrm{F}$ & ${ }^{\circ} \mathrm{C}$ & $\left({ }^{\circ} \mathrm{C} \times 1.8\right)+32$
\end{tabular}


the most commonly used active ingredients, such as mefenoxam and cyazofamid, has been reported in $P$. capsici populations (Dunn et al., 2010; Jackson et al., 2012), increasing the difficulty of controlling this disease chemically. Biocontrol efforts with Trichoderma and Bacillus species have not been shown to be effective in controlling disease (Gilardi et al., 2015). Current strategies for disease mitigation include growing less susceptible cultivars, planting non-vining cultivars in raised beds with plastic mulch to limit excessive soil moisture in the root zone, employing drip irrigation to reduce pathogen movement in surface water, and improving soil drainage with subsoil tillage and drainage tiles. Cultivars with increased resistance are highly desired for improved disease management.

To date, there are no squash or pumpkin cultivars available that are completely resistant to phytophthora crown and root rot. A previous study of 115 diverse squash and pumpkin accessions found partial resistance present in several accessions, but no accessions with complete resistance were identified (Padley et al., 2008). Additionally, cultivars have been shown to vary in their degree of susceptibility (Camp et al., 2009; Enzenbacher and Hausbeck, 2012; Meyer and Hausbeck, 2012). Crookneck summer squash and acorn squash cultivars (C. реро ssp. ovifera) are generally more susceptible to phytophthora root and crown rot than zucchini and pumpkin cultivars (C. pepo ssp. реро) (Krasnow et al., 2017). The range of resistance phenotypes present among squash and pumpkin accessions suggests that resistance is quantitative, controlled by many genes.

The current lack of cultivars resistant to phytophthora crown and root rot, partnered with the longevity of oospores in infested soil and the emergence of fungicide insensitivity, has resulted in severe challenges for cucurbit growers. As a result, breeding for resistance to phytophthora crown and root rot in squash and pumpkin began in 2011 at Cornell University (Ithaca, NY). Using disease assays conducted on seedlings in the greenhouse, we performed several rounds of selection to breed phytophthora-resistant (PR) lines. To determine the practical use of these lines, we concurrently initiated several trials to evaluate the performance of these lines in a field setting and in different greenhouse experiments. In this study, we describe the development of the PR lines and the results of our evaluations, which had the following objectives: 1) evaluate the resistance of the PR lines in trials in the field and the greenhouse, 2) evaluate the horticultural performance of the PR lines, and 3 ) evaluate the resistance of the PR lines relative to other accessions with partial resistance and against multiple isolates of $P$. capsici.

\section{Materials and methods}

Development of PR Lines. Two squash plant introduction (PI) accessions, PI 615089 and PI 179269, were selected as potential sources of resistance to oomycete pathogens and then crossed to several market classes of squash and pumpkin. The $\mathrm{F}_{1}$ progeny of these crosses were inoculated with $P$. capsici and selected for crown and root rot resistance in a field experiment, which led to the identification of a single family suitable for further advancement and selection. The parents of this family are PI 615089 and 'Romulus', and the PR lines described herein are derived from this family. PI 615089, also known as 'Austrian Bush', is a white vegetable marrow squash, and 'Romulus' is a zucchini cultivar released from Cornell University that was briefly commercially available. This family was advanced to the $\mathrm{F}_{2}$ generation, and the progeny were inoculated and selected for resistance in a field experiment. Cuttings were taken from the most resistant individuals of the $\mathrm{F}_{2}$ population. Three individuals survived the initial inoculation, a hail storm, remained disease free when the cuttings were rooted in water saturated soil in bags held at $30{ }^{\circ} \mathrm{C}$ and $100 \%$ relative humidity over the aerial portions of the cuttings, and were able to be selfpollinated. Beginning with the resulting $\mathrm{F}_{3}$ generation, selection for phytophthora crown and root rot resistance occurred in a greenhouse in every subsequent segregating generation. Seedlings were grown in 72-cell trays and inoculated with the pathogen at the second true leaf stage. Inoculation was performed as in the 2017 field disease trial, described below. After several weeks of disease and symptom progression, the most resistant plants in each generation were selected for self-pollination. Fifteen individual $\mathrm{F}_{3}$ plants from the three $\mathrm{F}_{2: 3}$ families were selected, self-pollinated, and the most resistant individual from each of the resulting $\mathrm{F}_{4}$ families was self-pollinated. The $\mathrm{F}_{5}$ families were then inoculated in a replicated design, and the three most resistant families were chosen as the PR lines included in the following evaluations. No significant differences were observed among the three selected families (data not shown). Selection continued concurrently with the evaluations described herein, resulting in three $\mathrm{F}_{7} \mathrm{PR}$ lines. These PR lines were also crossed with 'Dunja', a zucchini cultivar, and 'Kandy Korn Plus', a small pumpkin cultivar, to produce two zucchinitype and two pumpkin-type $\mathrm{F}_{1}$ hybrid lines. The $\mathrm{F}_{1}$ hybrids represent our efforts to incorporate the resistance observed in the PR lines into the zucchini and pumpkin market classes. The PR lines and $F_{1}$ hybrids were evaluated in the following study.

Evaluation of PR lines. Three field trials (2017 Early, 2017 Late, and 2018 field disease trials) and three greenhouse experiments were conducted to evaluate the level of resistance in the PR lines.

2017 Field disease trial. The purpose of the 2017 field disease trial was to evaluate the level of resistance to phytophthora crown and root rot of the PR lines under inoculated field conditions. The 12 cultivars, accessions, and lines included in this trial are described in Table 1. The seed lots of the three PR squash lines evaluated in this trial are as follows: Pc-NY2l (Lot 1610005), Pc-NY30 (Lot 16-10006), and Pc-NY32 (Lot 16-10007). The zucchini and pumpkin cultivars in this trial are representatives of their respective market classes. The accessions included in this trial are PI 615089 , the source of resistance for the PR lines; PI 181761, a squash accession reported to have partial resistance (Padley et al., 2008); and PI 211996, a tropical pumpkin (Cucurbita moschata) accession included as a resistant check (Chavez et al., 2011).

The 2017 field disease trial was conducted at the Phytophthora Blight Farm, located at Cornell AgriTech in 
Table 1. Squash and pumpkin cultivars, breeding lines, $F_{1}$ hybrids, and accessions used in trials for evaluating resistance to phytophthora crown and root rot.

\begin{tabular}{|c|c|c|c|c|}
\hline Line, cultivar, or accession & Type $^{\mathrm{z}}$ & Source & Location & Trialy $^{\mathrm{y}}$ \\
\hline 'Romulus’' & $\mathrm{zu}$ & Cornell University & Ithaca, NY & $\mathrm{P}$ \\
\hline 'Magic Lantern' & pn & Harris Seeds & Rochester, NY & FT \\
\hline 'Kandy Korn Plus' & pn & Holmes Seed Company & Canton, $\mathrm{OH}$ & FT \\
\hline 'Dunja' & $\mathrm{zu}$ & Johnny's Selected Seeds & Fairfield, ME & FT \\
\hline 'Spineless Beauty’x & $\mathrm{zu}$ & Harris Seeds & Rochester, NY & FT \\
\hline Pc-NY21 & $\mathrm{zu}$ & Cornell University & Ithaca, NY & FT, G2 \\
\hline Pc-NY30 & $\mathrm{pn}$ & Cornell University & Ithaca, NY & FT \\
\hline Pc-NY32 & $\mathrm{zu}$ & Cornell University & Ithaca, NY & FT, G3 \\
\hline 'Dunja' $\times$ Pc-NY21 F 1 & $\mathrm{zu}$ & $\mathrm{F}_{1}$ hybrid (this study) & - & FT \\
\hline 'Dunja' $\times$ Pc-NY32 F & $\mathrm{zu}$ & $\mathrm{F}_{1}$ hybrid (this study) & - & FT \\
\hline 'Kandy Korn Plus' × Pc-NY30 F & $\mathrm{pn}$ & $\mathrm{F}_{1}$ hybrid (this study) & - & FT \\
\hline 'Kandy Korn Plus' × Pc-NY32 F & pn & $\mathrm{F}_{1}$ hybrid (this study) & - & FT \\
\hline PI 615089 & $\mathrm{vm}$ & Cornell University & Ithaca, NY & FT, G2 \\
\hline PI 181761 & $\mathrm{pn}$ & Cornell University & Ithaca, NY & FT, G2 \\
\hline PI $211996^{\mathrm{w}}$ & bn & Cornell University & Ithaca, NY & FT \\
\hline PI 169417 & - & $\mathrm{NPGS}^{\mathrm{v}}$ & Ames, IA & G2 \\
\hline PI 174185 & - & NPGS & Ames, IA & G2 \\
\hline PI 179269 & - & NPGS & Ames, IA & G2 \\
\hline PI 209783 & - & NPGS & Ames, IA & G2 \\
\hline PI 266925 & - & NPGS & Ames, IA & G2 \\
\hline PI 512709 & - & NPGS & Ames, IA & G2 \\
\hline PI 615142 & - & NPGS & Ames, IA & G2 \\
\hline
\end{tabular}

${ }^{\mathrm{z}} \mathrm{pn}=$ pumpkin, $\mathrm{zu}=$ zucchini, $\mathrm{vm}=$ vegetable marrow, $\mathrm{bn}=$ butternut.

${ }^{y} \mathrm{P}=$ parental breeding line only; FT = yield field trial, phytophthora crown and root rot resistance field trials, and greenhouse Expt. 1 ; G2 = greenhouse Expt. 2; G3 = greenhouse Expt. 3.

${ }^{x}$ Spineless Beauty included only in the 2018 field disease trial.

${ }^{\text {w}}$ PI 211996 included only in the 2017 field disease trial.

National Plant Germplasm System.

Geneva, NY. Two experiments were performed (2017 Early and 2017 Late field disease trials), differing in the age of the plants when first inoculated. The field used for these experiments was free of overwintering populations of $P$. capsici. The soil type at the Phytophthora Blight Farm is Odessa silt loam (USDA, 2020).

Pre-emergent herbicide trifluralin was applied at a rate of $0.5 \mathrm{lb} /$ acre (Triflurex HFP; Adama, Raleigh, NC) $5 \mathrm{~d}$ before transplanting. Raised beds measuring $3 \mathrm{ft}$ wide by 4 inches high were formed and covered with 1.25-mil black, embossed plastic mulch (Belle Terre Irrigation, Sodus, NY). As mulch was laid, $300 \mathrm{lb} /$ acre 10N-4.4P-8.3K fertilizer (Phelps Supply, Phelps, NY) was applied to the beds. One drip tape line [12 inches between emitters and flow rate of $0.45 \mathrm{gal} / \mathrm{min}$ per $100 \mathrm{ft}$ (Toro, Bloomington, MN)] was laid underneath the mulch, slightly off center. Beds were spaced $6 \mathrm{ft}$ between centers for the 2017 Early field disease trial and $10 \mathrm{ft}$ between centers for the 2017 Late field disease trial.

Plants were started in a greenhouse in soilless potting media
(Sunshine Mix \#8; Sun Gro Horticulture, Agawam, MA) in 72-cell flats on 2 June. Seedlings were hardened off in an outdoor coldframe and transplanted to the field on 22 June. Transplants were planted in single rows with $2 \mathrm{ft}$ of in-row spacing. Plants were arranged in a randomized complete block design with three replications for each of the 2017 experiments. Experimental plots were $16 \mathrm{ft}$ long, containing eight plants, with $4 \mathrm{ft}$ of space between adjacent plots. At the time of transplant, $21 \mathrm{~N}-$ 2.2P-16.6K water-soluble fertilizer (Peters Excel; JR Peters, Allentown, PA) was applied with a water wheel transplanter at an approximate rate of $1.3 \mathrm{~g}$ of fertilizer per foot of row ( $2 \mathrm{lb}$ of fertilizer per gallon of water).

To control striped cucumber beetles (Acalymma vittatum), imidacloprid (Admire Pro; Bayer CropScience, Research Triangle Park, NC) was applied at the maximum labeled rate as a foliar spray after transplant. Plants that did not survive transplanting were replaced 1 week later. Plants were drip irrigated during the season to supplement rainfall, which totaled $3.8,6.8$, and 4.0 inches for the months of June, July, and August, respectively.

Phytophthora capsici isolate NY 0664-1 was used as a source of inoculum (Dunn et al., 2013). Isolates were induced to sporulate by culturing on plates of $15 \%$ unfiltered V8 agar for 7-10 d with $15 \mathrm{~h}$ of fluorescent lighting per day. Plates were then flooded with water and sporangia dislodged with an L-shaped spreading rod. Sporangial suspensions were incubated at room temperature for 30-45 min to promote release of zoospores. After quantifying with a hemocytometer, zoospore suspensions were diluted to the desired final concentration. Five $\mathrm{mL}$ of zoospore suspension was applied to the base of each plant using a 4-gal diaphragm pump backpack sprayer (Solo, Newport News, VA). Inoculation dates were 4 July, 11 July, and 18 July for the 2017 Early field disease trial and 19 July, 26 July, and 2 Aug. for the 2017 Late field disease trial. A concentration of $10^{4}$ zoospores $/ \mathrm{mL}$ was used for the first two inoculations of the 2017 Early field disease trial. All remaining inoculations of the 2017 Early and Late field disease trials were 
performed using a concentration of $10^{5}$ zoospores $/ \mathrm{mL}$.

Plots were rated for incidence of mortality at multiple time points. Mortality was defined as total plant wilting or necrosis of all shoot tips. Ratings were recorded at 10 time points from 11 July to 25 Aug. for the 2017 Early field disease trial and at seven time points from 21 July to 25 Aug. for the 2017 Late field disease trial.

2018 Field disease trial. The field disease trial described above was repeated in 2018. Because no significant differences were observed between the 2017 Early and 2017 Late field disease trials, all replicates of the 2018 field disease trial were inoculated at the same time. The PR lines and hybrids included in the 2017 field disease trials were included in the 2018 field disease trial (Table 1). However, PI 211996 was replaced with 'Spineless Beauty', a zucchini cultivar that was previously reported to have intermediate resistance to phytophthora crown and root rot (Meyer and Hausbeck, 2012). Plants were started as in the 2017 field disease trial, except the sowing date was 12 June and the transplant date was 3 July. The field was prepared with raised beds spaced $10 \mathrm{ft}$ between centers as described in the 2017 Late field disease trial, except no pre-emergent herbicide was applied. The plant spacing, fertilization, and experimental design was the same as described for 2017, except four replications were performed. Imidacloprid was applied as a transplant-water drench to control striped cucumber beetles. Plants that did not survive transplanting were replaced 1 week later to ensure all plots had eight plants. However, one plot of 'Spineless Beauty' and one plot of Pc-NY30 contained only six and seven plants, respectively, due to limited transplant availability. Plants were drip irrigated during the season to supplement rainfall, which totaled $2.7,3.2$, and 6.7 inches for the months of June, July, and August, respectively.

The plants in this experiment were inoculated with the same $P$. capsici isolate prepared in the same way as in the 2017 field disease experiment. Field inoculation occurred on 16 July using a concentration of $10^{5}$ zoospores $/ \mathrm{mL}$. Plots were rated for incidence of mortality at 11 time points from 20 July to 29 Aug.
Greenhouse Expt. 1. This experiment evaluated the resistance of the same set of 12 entries evaluated in the 2018 field disease experiment. The experiment was conducted in a greenhouse with the temperature maintained at $23.9 / 21.1{ }^{\circ} \mathrm{C}$ (day/ night). Seeds were sown in the same soilless potting media as was used for transplant production in the field disease trials, in 72-cell trays using a randomized complete block design with six replications. The 72-cell trays were selected for this experiment to mimic the environmental conditions used for selection of the PR lines. Experimental units consisted of columns of six cells, with each tray serving as a block.

Inoculum was prepared as in the field experiments. Plants were each inoculated with $2.5 \mathrm{~mL}$ of a zoospore suspension of $P$. capsici isolate NY 0664-1 at a concentration of $10^{4}$ zoospores $/ \mathrm{mL}$ that was pipetted adjacent to the plant on the surface of the potting media. The plants were inoculated at 2-3 weeks old, at the two-true leaf stage. Mortality ratings were recorded at six time points, beginning $3 \mathrm{~d}$ post inoculation (DPI) and proceeding every other day.

Greenhouse Expt. 2. This experiment compared the resistance of PR line Pc-NY21 to previously reported sources of partial phytophthora root and crown rot resistance (Table 1). The environmental conditions for this experiment were the same as described in greenhouse Expt. 1. Of the eight most resistant accessions from a previous screen of 115 diverse accessions (Padley et al., 2008), the seven with seed available from the U.S. National Plant Germplasm System were included in this experiment (Table 1$)$. In addition, the source of resistance for the PR lines, PI 615089, was included, as was PI 179269, an accession identified as partially resistant in previous experiments at Cornell University. 'Dunja' was included as a susceptible check. Because this experiment occurred concurrently with the other field and greenhouse experiments, seed was limited. Therefore, a different seed lot of Pc-NY21 (Lot 17-G-014) from the previous experiments was evaluated here. This Pc-NY2l seed lot is an $\mathrm{F}_{5: 6}$ family derived from a different $\mathrm{F}_{5}$ individual than the Pc-NY21 (Lot 1610005) described in the field trials above. A single representative PR line was included to conserve seed, as the three PR lines are closely related. This experiment was arranged as a completely randomized design with six replications, with each experimental unit consisting of a single plant in a 4inch square pot (Dillen, Middlefield, $\mathrm{OH})$. Inoculation occurred as previously described in greenhouse Expt. 1. Mortality ratings were recorded at 15 time points, beginning 3 DPI and proceeding every other day.

Greenhouse Expt. 3. This experiment compared the resistance of Pc-NY32 and 'Dunja' to three different pathogen isolates. The environmental conditions for this experiment were the same as described in greenhouse Expt. 1. As in greenhouse Expt. 2, a different seed lot of PcNY32 (Lot 17-G-009) was included in this experiment due to limited seed availability. This Pc-NY32 seed lot is an $\mathrm{F}_{5: 6}$ family derived from a different $\mathrm{F}_{5}$ individual than the Pc-NY32 (Lot 16-10007) described in the field trials above. As before, only a single PR line was evaluated due to limited seed, so Pc-NY32 was arbitrarily chosen to represent the PR lines. California isolate SJV-CA and New Mexico isolate PCNM-6300 were used in addition to isolate NY 0664-1 in this experiment. This experiment featured a full factorial arrangement of three pathogen isolates and the two squash lines. Experimental units consisted of six adjacent plants potted individually in 4 -inch pots, with experimental units arranged in a completely randomized design with three replications. Plants were inoculated as described in greenhouse Expt. 1. Mortality ratings were recorded at nine time points, beginning 3 DPI and proceeding every other day.

HorTiCUlTURAL PERFORMANCE. A field trial was conducted in 2017 at the East Ithaca Research Farm of Cornell University in Ithaca, NY, to evaluate the yield and horticultural performance of the PR lines, including evaluation of percent marketability, fruit shape, and plant habit. There is no history of P. capsici on this farm, and the plants were not inoculated. The lines evaluated in this trial consisted of the 12 entries evaluated in both the 2017 and 2018 field disease trials (i.e., excluding 'Spineless Beauty' and PI 211996; Table 1). A $5 \mathrm{~N}-1.3 \mathrm{P}-3.3 \mathrm{~K}$ fertilizer (Pro-Gro; 
North Country Organics, Bradford, $\mathrm{VT})$ and blood meal (12N-0P-0K; Down To Earth Fertilizer, Eugene, OR) were banded into the field, and raised beds that were $3 \mathrm{ft}$ wide and 4 inches tall were constructed, with 10 - $\mathrm{ft}$ spacing between the centers. The beds were covered with 1-mil embossed, black plastic mulch (Dubois Agrinovation, Saint-Rémi, QC, Canada), and drip tape [ 12 inches between emitters and flow rate of $0.45 \mathrm{gal} / \mathrm{min}$ per $100 \mathrm{ft}$ (Rain-Flo Irrigation, East Earl, PA)] was used for irrigation in the beds, placed slightly off center. The soil type of the East Ithaca Research Farm is Arkport fine sandy loam (USDA, 2020).

Plants for the 2017 yield trial were sown in soilless potting media [Cornell Mix (Boodley and Sheldrake, 1972)] in 72-cell trays on 29 May in a greenhouse. The plants were then transferred to an outdoor coldframe for 1 week for hardening off before being transplanted on 15 June. The transplants were planted into single rows with $2 \mathrm{ft}$ between plants within plots. The plants were arranged in a randomized complete block design with four replications. The experimental plots consisted of eight plants, with $4 \mathrm{ft}$ of space between adjacent experimental units. Plants were irrigated to supplement natural rainfall, which totaled 3.5, 5.7, 2.1, and 2.0 inches in June, July, August, and September, respectively.

Yield was measured at the East Ithaca field site beginning on 11 July. The zucchini-type lines were harvested about three times per week for 7 weeks. Fruit were harvested $\approx 3$ $\mathrm{d}$ after pollination and were categorized as marketable and unmarketable. Marketable fruit were at least 5 inches in length, straight, and blemish-free. Yield of both fruit classes were measured by total weight of fruit and total number of fruit. Total marketable fruit per plant and percent marketable yield per plant were calculated and used for subsequent analysis. On 31 July and 7 Aug., all harvested fruit were collected and the following measurements were made on individual fruit: fruit weight, fruit width at the widest point, and fruit length. Fruit shape, calculated as fruit length/fruit width, was then calculated for each fruit. The pumpkin-type lines were harvested at physiological maturity on 12 Sept. All fruit were counted and categorized as marketable or unmarketable. A fruit was considered unmarketable if large blemishes were present on its surface or if the fruit was misshapen. A random sample of 10 fruit per plot, as available, were selected for additional length, width, and weight measurements. Additionally, plant habit was determined, with each line characterized as bush type, semibush type, or vine type. A bush plant has a short (often upright) stem and compressed internode length. A vine type has a long stem, with long internodes, that creeps along the ground. A semibush type begins as a bush-type plant, with short internodes, and then the internodes of the main stem begin to elongate midseason, transitioning to a vine-type plant.

Statistics. The $\mathrm{R}$ statistical software ( $\mathrm{R}$ version 3.6.2; $\mathrm{R}$ Foundation for Statistical Computing, Vienna, Austria) was used for all analyses. For field disease trials and greenhouse experiments, disease incidence ratings were used to calculate the area under the disease progress curve [AUDPC (Cooke et al., 2006)]. Pearson correlations among the entry means of the field and greenhouse disease experiments were performed using the R package "Hmisc" (Harrell Jr., 2018). Analysis of variance (ANOVA) was performed for traits described above for each site and experiment, with block included as a random effect. Data from the 2017 Early and 2017 Late disease field trials were combined for analysis in a model including inoculation time and block as random effects. The package "Ismeans" (Lenth, 2016) was used to separate treatment means from all significant ANOVAs. Tukey's honestly significant difference test $(\alpha=0.05)$ was used to perform all pairwise comparisons and to generate connecting letter diagrams. In the yield trial, lines with zucchini-type fruit were harvested multiple times, and therefore the data for the following traits were summed across all harvest dates: number of marketable fruit per plant and percent marketable fruit per plant. The sums for these traits were used for analysis.

\section{Results}

Development of PR Lines. Inoculation and selection for phytophthora crown and root rot resistance resulted in the identification of three PR lines with resistance derived from PI 615089. These PR lines are $F_{6: 7}$ families from the following seed lots: Pc-NY21 (Lot 16-10005), Pc-NY30 (Lot 16-10006), and Pc-NY32 (Lot 16-10007). Four $F_{1}$ hybrids were included in the trials: two zucchini-type hybrids of 'Dunja' crossed to PcNY21 or Pc-NY32 and two pumpkin-type hybrids of 'Kandy Korn Plus' crossed to Pc-NY30 or Pc-NY32.

Evaluation of PR lines. The PR lines were among the most resistant entries in the disease experiments. Notably Pc-NY30 was consistently one of the most resistant lines over both years and locations (Table 2). Disease symptoms progressed rapidly in the susceptible lines, particularly in 'Magic Lantern'. Young plants displayed constriction of the crown, leading to wilting and plant collapse. Complete mortality in the young plant stage was observed in susceptible lines. Young plant mortality was less common in the PR lines. As the season progressed and the plants matured in the field, the disease symptoms that manifested in these lines more often consisted of death of the apical meristem.

2017 Field disease trial. Data from the 2017 Early field disease trial and 2017 Late field disease trial were combined for analysis. All three PR lines were significantly more resistant than 'Magic Lantern' and 'Dunja', the susceptible pumpkin and zucchini cultivars, respectively (Table 2 ). While not previously reported to possess resistance to phytophthora crown and root rot, 'Kandy Korn Plus' was not significantly different from the PR lines, although more disease was observed on this cultivar relative to the PR lines. Less disease was observed on the two zucchini-type $F_{1}$ lines, 'Dunja' $\times$ Pc-NY2l F 1 and 'Dunja' $\times$ PcNY32 $F_{1}$, relative to 'Dunja', although they were not significantly different, and only 'Dunja' $\times$ PcNY21 $F_{1}$ was significantly different from its breeding line parent. The two pumpkin-type $\mathrm{F}_{1}$ lines, 'Kandy Korn Plus' $\times$ Pc-NY30 $F_{1}$ and 'Kandy Korn Plus' $\times$ Pc-NY32 $F_{1}$, displayed a level of resistance that was not significantly different from that of the PR lines or 'Kandy Korn Plus'. Although not significantly more resistant, the PR lines had a lower AUDPC value relative to PI 615089, their resistant 
Table 2. Resistance of squash and pumpkin lines to phytophthora crown and root rot. The 2017 field disease trial and the 2018 field disease trial were conducted at the Phytophthora Blight Farm at Cornell AgriTech in Geneva, NY. Resistance was measured as area under the disease progress curve (AUDPC), using disease incidence ratings taken every $2 \mathrm{~d}$ for greenhouse Expt. 1 and about biweekly for the field trials.

\begin{tabular}{lccc}
\hline & \multicolumn{3}{c}{ AUDPC $^{\mathbf{z}}$} \\
\cline { 2 - 4 } Line, cultivar, or accession & $\mathbf{2 0 1 7}$ Field & $\mathbf{2 0 1 8}$ Field & Greenhouse Expt. 1 $^{\mathrm{y}}$ \\
\hline 'Magic Lantern' & $37.35 \mathrm{a}$ & $38.78 \mathrm{a}$ & $9.97 \mathrm{a}^{\mathrm{x}}$ \\
'Dunja' & $31.15 \mathrm{ab}$ & $35.45 \mathrm{a}$ & $9.86 \mathrm{a}$ \\
'Kandy Korn Plus' & $15.19 \mathrm{~cd}$ & $12.09 \mathrm{de}$ & $9.11 \mathrm{a}$ \\
'Spineless Beauty'w & - & $29.42 \mathrm{abc}$ & - \\
Pc-NY21 & $8.03 \mathrm{~d}$ & $20.77 \mathrm{bcde}$ & $7.14 \mathrm{ab}$ \\
Pc-NY30 & $6.03 \mathrm{~d}$ & $8.06 \mathrm{e}$ & $2.94 \mathrm{c}$ \\
Pc-NY32 & $13.16 \mathrm{~cd}$ & $21.09 \mathrm{bcde}$ & $2.87 \mathrm{c}$ \\
'Dunja' $\times$ Pc-NY21 F & $20.11 \mathrm{bc}$ & $25.38 \mathrm{abcd}$ & $8.17 \mathrm{ab}$ \\
'Dunja' $\times$ Pc-NY32 F & $21.49 \mathrm{bc}$ & $27.16 \mathrm{abc}$ & $5.75 \mathrm{bc}$ \\
'Kandy Korn Plus' $\times$ Pc-NY30 F & $5.49 \mathrm{~d}$ & $7.55 \mathrm{e}$ & $5.5 \mathrm{bc}$ \\
'Kandy Korn Plus' $\times$ Pc-NY32 F & $10.84 \mathrm{~cd}$ & $26.48 \mathrm{abc}$ & $3.42 \mathrm{c}$ \\
PI 615089 & $14.25 \mathrm{~cd}$ & $18.86 \mathrm{cde}$ & $8.08 \mathrm{ab}$ \\
PI 181761 & $26.91 \mathrm{ab}$ & $34.3 \mathrm{ab}$ & $8.01 \mathrm{ab}$ \\
PI 211996 & $4.44 \mathrm{~d}$ & - & - \\
\hline
\end{tabular}

${ }^{\mathrm{z}}$ Least squares means of AUDPC.

y2017 Early disease field trial and 2018 Late disease field trial were combined for analysis.

${ }^{\mathrm{x}}$ Means in the same column followed by the same letter are not significantly different at $P<0.05$ as determined by Tukey's honestly significant difference test.

whe zucchini cultivar Spineless Beauty is reported to have intermediate resistance to phytophthora crown and root rot and was included in the 2018 disease field trial as a replacement for PI 211996

"PI 211996 was included as a resistant check in the 2017 disease field trial.

parent (Table 2). The PR lines were also found to be significantly more resistant than PI 181761. No significant differences were found between the PR lines and PI 211996, the resistant tropical pumpkin accession.

2018 FIELD DISEASE TRIAL. The general trends in 2017 were also observed in the 2018 field disease trial (Table 2). All three PR lines were significantly more resistant than 'Magic Lantern' and 'Dunja'. Although the three PR lines were not significantly different from one another, Pc-NY21 and Pc-NY32 had a greater AUDPC than Pc-NY30. The two zucchinitype $\mathrm{F}_{1}$ lines continued to display intermediate resistance, although they were not significantly different from 'Dunja', and only 'Dunja' $\times$ Pc-NY32 $F_{1}$ was significantly different from its breeding line parent. The pumpkin-type $\mathrm{F}_{1}$ lines, 'Kandy Korn Plus' $x$ Pc-NY30 $F_{1}$ and 'Kandy Korn Plus' $\times$ Pc-NY32 $F_{1}$, were not significantly different from either of their PR line parents, Pc-NY30 and Pc-NY32, respectively. 'Kandy Korn Plus' was not significantly different from the PR lines in this trial, and 'Kandy Korn Plus' $\times$ Pc-NY32 $\mathrm{F}_{1}$ displayed a greater AUDPC than either of the parents. In 2018, 'Spineless Beauty' was included in place of PI 211996 as a partially resistant zucchini check. 'Spineless Beauty' had a greater AUDPC than any of the PR lines, but only Pc-NY30 was significantly different.

Greenhouse Expt. 1. The disease experiments conducted in the field in 2017 and 2018 were repeated in greenhouse Expt. 1 in 2018. Pc-NY30 and Pc-NY32 were the most resistant lines in the experiment and were significantly different from the commercial cultivars and the two partially resistant accessions. Pc-NY21, on the other hand, was not significantly different from the most susceptible entries. The resistance observed in the hybrids varied. The two hybrids with 'Kandy Korn Plus' as a parent were significantly more resistant than 'Kandy Korn Plus' and statistically like their breeding line parents. Of the 'Dunja' hybrids, only 'Dunja' $\times$ Pc-NY32 $F_{1}$ was significantly more resistant than 'Dunja', and both were statistically similar to their breeding line parents (Table 2).

The correlations among the entry means from the 2017 disease field trial, 2018 disease field trial, and greenhouse Expt. I were calculated. Data from the 2017 Early field disease trial and 2017 Late field disease trial were combined. The two field trials were strongly and significantly correlated, with a correlation coefficient of 0.87 at $P<0.001$. Greenhouse Expt. 1 was also significantly correlated with the 2017 disease field trial, with a correlation coefficient of $0.69(P=$ $0.012)$. However, greenhouse Expt. 1 only had a moderate correlation with the 2018 disease field trial [ $r=$ 0.48 (not significant)].

GreENHOUSE EXPT. 2. In greenhouse Expt. 2, PR line Pc-NY2l was ranked lowest in AUDPC among all the partially resistant accessions and was significantly more resistant to over half of lines in the experiment (Table 3). PI 615089 was the second lowest ranked in AUDPC, although it was not significantly different from most entries in the experiment. Most accessions displayed partial resistance, with intermediate AUDPC values compared with Pc-NY2l and the susceptible check 'Dunja'.

Greenhouse ExPT. 3. Greenhouse Expt. 3 evaluated the response of two squash lines, Pc-NY32 and 'Dunja', to three geographically diverse $P$. capsici isolates. Clear, significant differences were observed between the two lines. By 12 DPI, the average incidence of mortality for all isolates on 'Dunja' was $90 \%$ or greater (Fig. 1). No mortality was observed on any Pc-NY32 plants, regardless of isolate. These differences due to line were highly significant $(P<0.001)$. However, there were no significant differences due to the isolate with which the two lines were inoculated $(P=0.110)$; all isolates caused similar levels of disease. Additionally, there was no significant lineby-isolate interaction observed $(P=$ 0.521 ).

Horticultural performance. The entries of the 2017 yield trial were divided into zucchini-type lines (Table 4) and pumpkin-type lines (Table 5). The zucchini-type lines were harvested over the course of 7 weeks, with 'Dunja' yielding the most marketable fruit and the two PR lines, Pc$\mathrm{NY} 21$ and $\mathrm{Pc}-\mathrm{NY} 32$, yielding the least marketable fruit over time (Fig. 2). The PR lines produced significantly fewer marketable fruit per plant than 'Dunja', as well as a significantly lower percentage of marketable fruit from the total yield (Table 4), whereas the $F_{1}$ lines were not significantly different 
Table 3. Area under the disease progress curve (AUDPC) means from greenhouse Expt. 2 for squash accessions with reported partial resistance to phytophthora crown and root. Disease incidence ratings were taken about every $2 \mathrm{~d}$.

\begin{tabular}{ll}
\hline Cultivar or breeding line & AUDPC $^{\mathbf{z}}$ \\
\hline 'Dunja' & $32.00 \mathrm{a}$ \\
PI 266925 & $29.00 \mathrm{ab}$ \\
PI 209783 & $27.00 \mathrm{abc}$ \\
PI 169417 & $26.67 \mathrm{abc}$ \\
PI 512709 & $26.00 \mathrm{abc}$ \\
PI 615142 & $25.00 \mathrm{abc}$ \\
PI 174185 & $22.42 \mathrm{abcd}$ \\
PI 181761 & $16.33 \mathrm{abcd}$ \\
PI 179269 & $14.08 \mathrm{bcd}$ \\
PI 615089 & $11.33 \mathrm{~cd}$ \\
Pc-NY21 & $8.17 \mathrm{~d}$ \\
\hline
\end{tabular}

${ }^{\mathrm{z}}$ Least squares mean of AUDPC.

${ }^{y}$ Means in the same column followed by the same letter are not significantly different at $P<0.05$ as determined by Tukey's honestly significant difference test.

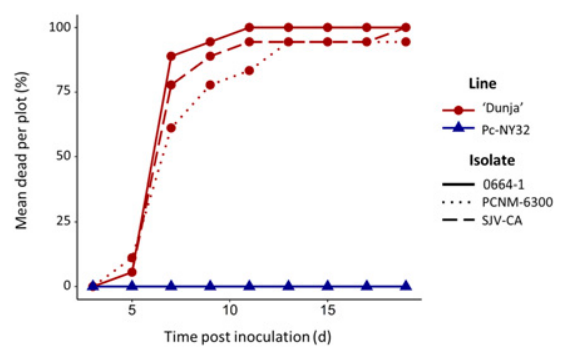

Fig. 1. Incidence of mortality over time in greenhouse Expt. 3 for phytophthora-resistant squash breeding line Pc-NY21 and susceptible zucchini 'Dunja' inoculated with three isolates of Phytophthora capsici.

from 'Dunja' for both traits. PI 615089 was intermediate in both its marketable yield and percent marketable fruit. Pc-NY21, as well as the $F_{1}$ lines, were not significantly different from 'Dunja' in fruit weight, but Pc-NY32 weighed significantly more. Only 'Dunja' $\times$ Pc-NY2l F was not significantly different from the long, narrow fruit shape value of 'Dunja'. All other lines were significantly shorter and wider than 'Dunja', with Pc-NY32 having the lowest length/width ratio of 2.64. 'Dunja' and PI 615089 were bush-type lines, but the two PR lines were the vine type, leading to semibush-type $\mathrm{F}_{1}$ lines.

The pumpkin-type lines in the 2017 yield trial were harvested at physiological maturity. 'Kandy Korn Plus' produced significantly more marketable fruit than the other lines, with 'Magic Lantern', Pc-NY30, and PI 181761 producing significantly fewer fruit, about one per plant ( $\mathrm{Ta}$ ble 5 ). The $F_{1}$ lines produced an intermediate number of fruit, about three per plant. However, there were no significant differences among the lines in the percentage of marketable fruit produced. Fruit weight varied significantly among the lines, with 'Magic Lantern' producing the largest fruit by weight and 'Kandy Korn Plus' producing the smallest fruit. PcNY30, PI 181761, and the $\mathrm{F}_{1}$ lines produced intermediate size fruit. PcNY30 was significantly longer and narrower than the rest of the lines. 'Magic Lantern' and 'Kandy Korn Plus' were about round-fruited, and PI 181761 and the $F_{1}$ lines produced intermediate, slightly elongated fruit. 'Kandy Korn Plus' was a bushtype plant, and Pc-NY30 was a vinetype plant. The $\mathrm{F}_{1}$ lines were both semibush-type plants, as was 'Magic Lantern'.

\section{Discussion}

As phytophthora crown and root rot continues to spread and threaten cucurbit crops, development of resistant cultivars becomes an increasingly urgent goal. In this study, three squash breeding lines selected for phytophthora crown and root rot resistance were evaluated for their yield and disease resistance. The PR breeding lines displayed significantly improved resistance over the susceptible cultivars Magic Lantern and Dunja. They also exhibited increased resistance relative to PI 615089, the resistant parent of the PR lines, although these differences were not statistically significant in either year of the field trial. Although there was variability across the 2017 and 2018 field and greenhouse disease experiments, the PR lines were generally the most resistant lines in the trials. Notably, Pc-NY30 was consistently among the most resistant group of lines in all three experiments. Pc-NY21 and Pc-NY32 displayed less stable resistance, although only in greenhouse Expt. I was the performance of one of these lines (Pc-NY21) significantly different from Pc-NY30.

The mechanisms of resistance to phytophthora crown and root rot in the PR lines remain to be elucidated. With other wilt-causing diseases of cucurbits, host resistance is associated with the inability of the pathogen to cause disruptions or occlusions in the vascular system (Main and Walker, 1971; Martyn, 1983). Histological comparisons between a phytophthora crown and root rot-susceptible and partially resistant squash cultivar revealed increased hyphal colonization of crown tissue and a greater incidence of occlusions of xylem vessels in the susceptible cultivar. The partially resistant cultivar, on the other hand, featured more numerous and lignified metaxylem vessels that withstood infection to continue to provide structural support of the plant (Krasnow et al., 2017). Similar mechanisms exist in pepper, where phytophthora crown and root rotresistant cultivars are able to prevent pathogen invasion of vascular tissue by limiting hyphal growth to the epidermis and outermost cortical layers of the roots and stems (Dunn and Smart, 2015; Kim and Kim, 2009). Preliminary microscopy studies of Pc-NY32 and 'Dunja' roots post-inoculation also showed a decreased presence of mycelia in the vascular bundles of Pc-NY32 (data not shown).

The variability observed in the disease resistance of the lines across environments is likely due to the hypothesized genetic complexity of resistance in squash and pumpkin and the strong influence of environmental factors on disease severity. Greenhouse Expt. 1 closely mimicked the selection environment of the PR lines, and resulted in strong, significant differences between the PR lines and all cultivars evaluated. The field disease trials, however, represented an environment more typical of the expected growing conditions of squash in the northeastern United States. The differences in environment, as well as the differences in the growth stage of the plants, led to significant rank changes between the field and greenhouse experiments. A previous study similarly found the phytophthora crown and root rot resistance of two squash cultivars to respond differentially to changes in growing conditions (Meyer and Hausbeck, 2012). The most dramatic change observed in this study was the increased level of field resistance 
Table 4. Yield and horticultural characteristics of zucchini-type phytophthora-resistant squash breeding lines and $\mathrm{F}_{1}$ hybrids evaluated in the 2017 yield trial at the East Ithaca Research Farm of Cornell University in Ithaca, NY. Fruit were harvested three times per week for 7 weeks, $\approx 2$ or $3 \mathrm{~d}$ after pollination.

\begin{tabular}{|c|c|c|c|c|c|}
\hline Cultivar or breeding line & Marketable fruit (no./plant) ${ }^{\mathrm{z}}$ & Marketable fruit $(\%)^{\mathrm{y}}$ & Fruit wt $(g)^{x}$ & Fruit shape $^{\mathrm{w}}$ & Plant habit \\
\hline 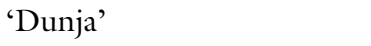 & $9.59 \mathrm{a}^{\mathrm{v}}$ & $85.03 \mathrm{a}$ & $272.0 \mathrm{~b}$ & $4.25 \mathrm{a}$ & Bush \\
\hline 'Dunja' $\times$ Pc-NY21 F & $7.22 \mathrm{ab}$ & $76.41 \mathrm{ab}$ & $358.2 \mathrm{ab}$ & $4.09 \mathrm{a}$ & Semi-bush \\
\hline 'Dunja' $\times$ Pc-NY32 F & $8.63 \mathrm{a}$ & $87.39 \mathrm{a}$ & $413.3 \mathrm{ab}$ & $3.50 \mathrm{~b}$ & Semi-bush \\
\hline Pc-NY21 & $2.91 \mathrm{~b}$ & $45.27 \mathrm{c}$ & $376.0 \mathrm{ab}$ & $3.10 \mathrm{c}$ & Vine \\
\hline Pc-NY32 & $3.22 \mathrm{~b}$ & $52.65 \mathrm{bc}$ & $479.5 \mathrm{a}$ & $2.64 \mathrm{~d}$ & Vine \\
\hline PI 615089 & $5.63 \mathrm{ab}$ & $66.72 \mathrm{abc}$ & $250.9 \mathrm{~b}$ & $3.62 \mathrm{~b}$ & Bush \\
\hline
\end{tabular}

${ }^{\mathrm{z}}$ Least squares mean of the total number of marketable fruit per plant across all replicates and harvest dates.

${ }^{y}$ Least squares mean of the percent marketable fruit across all replicates and harvest dates.

${ }^{\mathrm{x}}$ Least squares mean of individual fruit weight calculated by measuring all fruit per plot across all replicates on two harvest dates; $1 \mathrm{~g}=0.0353 \mathrm{oz}$.

${ }^{w}$ Least squares mean of fruit shape calculated from measurement of all fruit per plot across all replicates on two harvest dates. Fruit shape was calculated as fruit length/fruit width

${ }^{\mathrm{v}}$ Means in the same column followed by the same letter are not significantly different at $P<0.05$ as determined by Tukey's honestly significant difference test.

Table 5. Yield and horticultural characteristics of pumpkin-type phytophthora-resistant breeding lines evaluated in the 2017 yield trial at the East Ithaca Research Farm of Cornell University in Ithaca, NY.

\begin{tabular}{|c|c|c|c|c|c|}
\hline Cultivar or breeding line & $\begin{array}{c}\text { Marketable fruit } \\
{\text { (no./plant })^{\mathrm{z}}}\end{array}$ & Marketable (\%) & Fruit wt $(\mathrm{kg})^{\mathrm{x}}$ & Fruit shapew $^{\mathrm{w}}$ & Plant habit \\
\hline 'Magic Lantern’' & $1.06 \mathrm{c}^{\mathrm{v}}$ & $82.45 \mathrm{a}$ & $4.04 \mathrm{a}$ & $1.03 \mathrm{~d}$ & Semi-bush \\
\hline 'Kandy Korn Plus' × Pc-NY30 F & $3.25 \mathrm{~b}$ & $95.79 \mathrm{a}$ & $0.85 \mathrm{c}$ & $1.36 \mathrm{c}$ & Semi-bush \\
\hline 'Kandy Korn Plus' × Pc-NY32 F & $3.09 \mathrm{~b}$ & $96.07 \mathrm{a}$ & $1.13 \mathrm{bc}$ & $1.34 \mathrm{c}$ & Semi-bush \\
\hline Pc-NY30 & $1.19 \mathrm{c}$ & 85.99 a & $1.26 \mathrm{bc}$ & $2.24 \mathrm{a}$ & Vine \\
\hline
\end{tabular}

${ }^{\mathrm{z}}$ Least squares mean of the number of marketable fruit per plant across all replicates.

${ }^{y}$ Least squares mean of the percent marketable fruit across all replicates.

${ }^{\mathrm{x}}$ Least squares mean of individual fruit weight calculated from 10 fruit per plot across all replicates; $1 \mathrm{~kg}=2.2046 \mathrm{lb}$.

wLeast squares mean of fruit shape calculated from measurement of 10 fruit per plot across all replicates. Fruit shape was calculated as fruit length/fruit width.

${ }^{\mathrm{v}} \mathrm{Means}$ in the same column followed by the same letter are not significantly different at $P<0.05$ as determined by Tukey's honestly significant difference test.

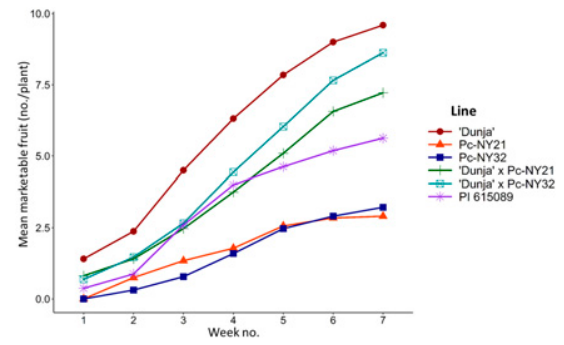

Fig. 2. Cumulative marketable yield of zucchini-type lines over time in the 2017 yield trial at the East Ithaca Research Farm of Cornell University in Ithaca, NY. Yield is represented by the total number of marketable fruit per plant averaged across four replicates.

displayed by 'Kandy Korn Plus'. In greenhouse Expt. 1, 'Kandy Korn Plus' was as susceptible as 'Dunja' and 'Magic Lantern' when inoculated in 72-cell trays, displaying severe constriction and rot at the base of the stem that lead to rapid whole plant collapse. The PR lines displayed significantly less stem rot and mortality in greenhouse Expt. 1. However, 'Kandy Korn Plus' was not significantly different from the PR lines in the field. Field conditions appeared to be more favorable for plant growth than the 72-cell trays used for the greenhouse inoculation experiment, but 'Kandy Korn Plus' displayed a pronounced differential response in the field that was not observed in the other entries of the trial. In the field, 'Dunja' and 'Magic Lantern' rapidly developed stem rot leading to total plant collapse shortly after inoculation. As in greenhouse Expt. 1 , the PR lines displayed much less stem rot and rapid plant collapse upon inoculation than the susceptible lines. However, unlike greenhouse Expt. 1, 'Kandy Korn Plus' also displayed reduced mortality upon inoculation. Growth architecture may have also contributed to the increased resistance observed in 'Kandy Korn Plus'. As the disease continued to progress, less mortality by whole plant collapse was observed, but mortality by necrosis of all shoot tips increased. The bush-type 'Kandy Korn Plus' plants featured multiple growing points and were therefore capable of withstanding mild disease symptoms and necrosis of several shoot tips without complete plant death. The PR lines were highly apically dominant, with many plants having a single shoot tip, and thus were more vulnerable to mortality by total shoot tip necrosis. Therefore, compared with the breeding lines, the favorable plant architecture of 'Kandy Korn Plus' at later stages of infection in the field may have compensated for its weaker resistance response at early stages of infection that made it highly susceptible in the greenhouse environment. This suggests that 'Kandy Korn Plus' may contain beneficial alleles for increased resistance to phytophthora crown and root rot; and more generally, that bush-type plants with multiple growing points, although not typical for zucchini and summer squash, could represent a desirable growth habit for phytophthora crown and root 
rot-resistant lines. Future screening of additional cultivars may identify additional sources of partial resistance that could improve breeding efforts.

Pumpkin-type and zucchini-type $\mathrm{F}_{1}$ hybrids were evaluated in these experiments to determine the use of the PR lines as parents for resistant, horticulturally acceptable hybrid cultivars. In greenhouse Expt. 1 , the $F_{1}$ hybrids displayed intermediate resistance, not significantly different from their respective resistant parents. The hybrids also displayed intermediate resistance in the field, although the 'Dunja' hybrids were not significantly different from 'Dunja'. The 'Kandy Korn Plus' hybrids, particularly 'Kandy Korn Plus' $\times$ Pc-NY30 F , displayed levels of resistance comparable to the PR lines. Overall, the disease ratings of the $\mathrm{F}_{1}$ hybrids indicate that incorporating the PR lines as hybrid parents may provide partial resistance, although the resistance of the progeny is highly dependent on the second parent.

The entries included in greenhouse Expt. 2 represent the most resistant squash and pumpkin accessions identified to date (Padley et al., 2008). Pc-NY21 was the most resistant of all entries in this study, suggesting that this line contains novel alleles or allelic combinations that are not present in the other accessions evaluated. However, the presumed quantitative basis of resistance indicates that the other partially resistant accessions likely possess beneficial alleles that may not be present in the PR lines. The resistant accessions identified by Padley et al. (2008) have since been genotyped with simple sequence repeat markers and revealed to be genetically like cultivars representing zucchini and pumpkin morphotypes (Michael et al., 2019). The resistance levels of the PR lines could potentially be improved by the incorporation of additional beneficial alleles from these accessions.

In the experiments described above, two different seed lots of PcNY21 were used, with Lot 16-10005 used for the 2017 field disease trial, 2018 field disease trial, and greenhouse Expt. 1; and Lot 17-G-014 used for greenhouse Expt. 2. These seed lots represent $\mathrm{F}_{5: 6}$ families derived from separate $\mathrm{F}_{5}$ individuals. Two different seed lots were necessary due to limited seed availability because these experiments occurred concurrently with breeding efforts. In greenhouse Expt. 2, Pc-NY21 (Lot 17-G-014) was highly resistant, but Lot 16-10005 was variable across the other experiments, suggesting that Lot 16-10005 was still segregating for resistance. Because these seed lots are not completely fixed for resistance, further selection and selfing of the most resistant individuals is important to develop stable, resistant lines for further characterization.

No line-by-isolate interactions were identified in greenhouse Expt. 3 , suggesting that the resistance present in the PR lines may be robust to diverse isolates of P. capsici. Phytophthora capsici is a genetically diverse species, with sexual reproduction common in populations in the United States (Bowers et al., 2007; QuesadaOcampo et al., 2011). In pepper, numerous reports support the existence of physiological races of $P$. capsici that display differential virulence patterns on different host lines (Glosier et al., 2008; Hwang et al., 1996; Monroy-Barbosa and Bosland, 2008; Oelke et al., 2003), necessitating different sources of resistance for specific isolates. In cucurbits, a previous experiment found a significant interaction effect between crop type and pathogen isolate on phytophthora crown and root rot disease severity in the greenhouse (Enzenbacher and Hausbeck, 2012), but further research is necessary to understand the extent to which differential isolateline interactions exist in squash. PR lines with robust resistance to $\mathrm{di}$ verse $P$. capsici isolates are particularly desirable for the development of new resistant cultivars with broad adaptability.

The PR lines were significantly different from the commercial cultivars in almost all aspects measured in the yield trial. Pc-NY21 and Pc-NY32 yielded significantly fewer marketable fruit than 'Dunja', with a lower percentage of their fruit being marketable overall. However, the yield of the $\mathrm{F}_{1}$ lines was not significantly different from 'Dunja', suggesting that this yield deficit can be restored by crossing with a high-yielding zucchini cultivar. The fruit shape of these PR lines was also significantly shorter and wider than an ideal zucchini, which is long and cylindrical (Paris, 1996). This typical zucchini fruit shape was recovered in the $F_{1}$ lines, particularly 'Dunja' $\times$ Pc-NY21 F $F_{1}$. The vining habit of the PR lines is also unacceptable for zucchini cultivars, which have a bush growth habit, by definition (Paris, 1996). The rapid recovery of acceptable yield and fruit characteristics in the $F_{1}$ lines suggest that the PR lines can produce marketable zucchini cultivars when incorporated into a breeding program, although it may be challenging to simultaneously retain all disease-resistance alleles.

The pumpkin-type PR line, PcNY30, displayed use as a parent for new phytophthora crown and root rot-resistant pumpkin cultivars. Although the fruit shape of this line was significantly longer than the ideal length/width ratio $(\approx 1)$ for a typical pumpkin cultivar (Paris, 1996), the $\mathrm{F}_{1}$ lines with 'Kandy Korn Plus' displayed a desirable fruit shape. These lines also had increased yield of highly marketable fruit. 'Kandy Korn Plus' produced many small fruit, and therefore the fruit of the $\mathrm{F}_{1}$ lines were also small. Pairing Pc-NY30 with a larger jack-o'-lantern-type pumpkin to generate a new hybrid is necessary for future production of new resistant jack-o'-lantern-type pumpkins.

Phytophthora fruit rot is another disease symptom caused by $P$. capsici that is often a major limitation to cucurbit production (Babadoost, 2000, 2004; Babadoost and Zitter, 2009). Fruit rot infections can be so severe that fields are left unharvested and truckloads of fruit are rejected (Hausbeck and Lamour, 2004). Fruit may become infected through contact with infested soil or when the pathogen is dispersed during rainfall or irrigation. Symptoms typically begin with a water-soaked lesion, leading to sporulation and rapid fruit collapse (McGrath, 2017). Previous studies suggest that genetic resistance to phytophthora fruit rot may be present among Cucurbita species (Ando et al., 2009; Krasnow et al., 2014), although age-related resistance is the most common type of fruit rot resistance (Ando et al., 2009; Krasnow and Hausbeck, 2016; Meyer and Hausbeck, 2013a). Hard-rind pumpkin cultivars with reduced susceptibility to phytophthora fruit rot are available, but relatively high incidence of disease has been reported (McGrath and Fox, 2008), and the hard-rind trait renders the fruit 
unsuitable for carving into jack-o'lanterns. Preliminary studies suggest that age-related resistance may be present in the PR lines (data not shown); however, observations of fruit rot in the field disease trials suggests that the PR lines do not possess sufficient levels of resistance for practical use. Although the vining PR lines quickly spread to the soil between the rows, the semibush $\mathrm{F}_{1}$ pumpkin-type lines produced most of their fruit on the plastic mulch. By growing lines with a semibush or bush growth habit on plastic mulch and raised beds, the incidence of fruit rot may be reduced by separating the fruit from infested soil (Ando and Grumet, 2006; Hausbeck and Lamour, 2004).

\section{Conclusion}

The PR lines described in this study represent a new resource for breeding phytophthora crown and root rot-resistant zucchini and pumpkin cultivars. They have demonstrated improved performance over previously identified sources of partial resistance. Additional breeding is necessary to achieve a highly marketable cultivar, but the hybrids evaluated in this study suggest that desirable phenotypes and resistance can be achieved. Phytophthora crown and root rot will continue to be a devastating disease, requiring a combined approach of cultural practices, fungicides, and host resistance for adequate control. By combining the resistance found in the PR lines with alleles from other potential sources, such as PI accessions and commercial cultivars, a more complete form of resistance may be attained.

\section{Literature cited}

Ando, K. and R. Grumet. 2006. Evaluation of altered cucumber plant architecture as a means to reduce Phytophthora capsici disease incidence on cucumber fruit. J. Amer. Soc. Hort. Sci. 131:491498.

Ando, K., S. Hammar, and R. Grumet. 2009. Age-related resistance of diverse cucurbit fruit to infection by Phytophthora capsici. J. Amer. Soc. Hort. Sci. 134:176182.

Babadoost, M. 2000. Outbreak of phytophthora foliar blight and fruit rot in processing pumpkin fields in Illinois. Plant Dis. 84:1345.
Babadoost, M. 2004. Phytophthora blight: A serious threat to cucurbit industries. I June 2020. <https://www. apsnet.org/edcenter/apsnetfeatures/ Pages/PhytophthoraBlight.aspx $>$.

Babadoost, M. and S.Z. Islam. 2003. Fungicide seed treatment effects on seedling damping-off of pumpkin caused by Phytophthora capsici. Plant Dis. 87:63-68.

Babadoost, M. and T.A. Zitter. 2009. Fruit rots of pumpkin: A serious threat to the pumpkin industry. Plant Dis. 93:772782.

Boodley, J.W. and R. Sheldrake, Jr. 1972. Cornell peat-lite mixes for commercial plant growing. New York College Agr., Cornell Univ., Inf. Bul. 43.

Bowers, J.H., F.N. Martin, P.W. Tooley, and E.D.M.N. Luz. 2007. Genetic and morphological diversity of temperate and tropical isolates of Phytophthora capsici. Phytopathology 97:492-503.

Camp, A., H. Lange, S. Reiners, H. Dillard, and C.D. Smart. 2009. Tolerance of summer and winter squash lines to phytophthora blight, 2008. Plant Dis. Manag. Rep. 3:V022.

Carlson, M.O., E. Gazave, M.A. Gore, and C.D. Smart. 2017. Temporal genetic dynamics of an experimental, biparental field population of Phytophthora capsici. Front. Genet. 8:1-19.

Chavez, D.J., E.A. Kabelka, and J.X. Chaparro. 2011. Screening of Cucurbita moschata Duchesne germplasm for crown rot resistance to Floridian isolates of Phytophthora capsici Leonian. HortScience 46:536-540.

Cooke, B.M., D.G. Jones, and B. Kaye. 2006. The epidemiology of plant diseases. 2nd ed. Springer, Dordrecht, The Netherlands.

Dunn, A.R., B.A. Fry, T.Y. Lee, K.D. Conley, V. Balaji, W.E. Fry, A. McLeod, and C.D. Smart. 2013. Transformation of Phytophthora capsici with genes for green and red fluorescent protein for use in visualizing plant-pathogen interactions. Australas. Plant Pathol. 42:583-593.

Dunn, A.R., M.G. Milgroom, J.C. Meitz, A. McLeod, W.E. Fry, M.T. McGrath, H.R. Dillard, and C.D. Smart. 2010. Population structure and resistance to mefenoxam of Phytophthora capsici in New York State. Plant Dis. 94:14611468.

Dunn, A.R and C.D. Smart. 2015. Interactions of Phytophthora capsici with resistant and susceptible pepper roots and stems. Phytopathology 105:1355-1361.

Enzenbacher, T.B. and M.K. Hausbeck. 2012. An evaluation of cucurbits for susceptibility to cucurbitaceous and solanaceous Phytophthora capsici isolates. Plant Dis. 96:1404-1414.

Gilardi, G., S. Demarchi, M.L. Gullino, and A. Garibaldi. 2015. Nursery treatments with non-conventional products against crown and root rot, caused by Phytophthora capsici, on zucchini. Phytoparasitica 43:501-508.

Glosier, B.R., E.A. Ogundiwin, G.S. Sidhu, D.R. Sischo, and J.P. Prince. 2008. A differential series of pepper (Capsicum annuum) lines delineates fourteen physiological races of Phytophthora capsici: Physiological races of $P$. capsici in pepper. Euphytica 162:23-30.

Granke, L.L., L. Quesada-Ocampo, and M.K. Hausbeck. 2012. Advances in research on Phytophthora capsici on vegetable crops in the United States. Plant Dis. 95:1588-1600.

Harrell, F.E., Jr. 2018. Hmisc: Harrell miscellaneous. 7 Aug. 2020. <https:// CRAN.R-project.org $/$ package $=$ Hmisc $>$.

Hausbeck, M.K. and K.H. Lamour. 2004. Phytophthora capsici on vegetable crops: Research progress and management challenges. Plant Dis. 88:1292-1303.

Hwang, B.K., Y.T. Kim, and C.H. Kim. 1996. Differential interactions of Phytophthora capsici isolates with pepper genotypes at various plant growth stages. Eur. J. Plant Pathol. 102:311316.

Jackson, K.L., J. Yin, and P. Ji. 2012. Sensitivity of Phytophthora capsici on vegetable crops in Georgia to mandipropamid, dimethomorph and cyazofamid. Plant Dis. 96:1337-1342.

Jones, L.A., R.W. Worobo, and C.D. Smart. 2014. Plant-pathogenic oomycetes, Escherichia coli strains, and Salmonella spp. frequently found in surface water used for irrigation of fruit and vegetable crops in New York state. Appl. Environ. Microbiol. 80:4814-4820.

Kim, S.G. and Y.H. Kim. 2009. Histological and cytological changes associated with susceptible and resistant responses of chili pepper root and stem to Phytophthora capsici infection. Plant Pathol. J. 25:113120.

Krasnow, C.S., R. Hammerschmidt, and M.K. Hausbeck. 2017. Characteristics of resistance to phytophthora root and crown rot in Cucurbita pepo. Plant Dis. 101:659-665.

Krasnow, C.S. and M.K. Hausbeck. 2016. Evaluation of winter squash and pumpkin cultivars for age-related resistance to Phytophthora capsici fruit rot. HortScience 51:1251-1255. 
Krasnow, C.S., R.P. Naegele, and M.K. Hausbeck. 2014. Evaluation of fruit rot resistance in cucurbita germplasm resistant to Phytophthora capsici crown rot. HortScience 49:285-288.

Kreutzer, W.A. 1937. A phytophthora rot of cucumber fruit. Phytopathology 27:955

Lamour, K.H., R. Stam, J. Jupe, and E. Huitema. 2012. The oomycete broadhost-range pathogen Phytophthora capsici. Mol. Plant Pathol. 13:329-337.

Lenth, R.V. 2016. Least-squares means: The R package lsmeans. J. Stat. Software 69:1-33.

Leonian, L.H. 1922. Stem and fruit blight of peppers caused by Phytophthora capsici sp. nov. Phytopathology 12:401-408.

Main, C.E. and J.C. Walker. 1971. Physiological responses of susceptible and resistant cucumber to Erwinia tracheiphila. Phytopathology 61:518-522.

Martyn, R.D. 1983. Susceptibility of summer squash to the watermelon wilt pathogen (Fusarium oxysporum f. sp. niveum). Plant Dis. 67:263-266.

McGrath, M.T. 2017. Phytophthora crown and root rot, p. 43-44. In: A.P Keinath, W.M. Wintermantel, and T.A. Zitter (eds.). Compendium of cucurbit diseases and pests. 2nd ed. American Phytopathological Society, Saint Paul, MN.
McGrath, M.T. and G.M. Fox. 2008. Hard-rind pumpkin cultivar evaluation for phytophthora fruit rot, 2008. Plant Dis. Mgt. Rep. 3:V126.

Meyer, M.D. and M.K. Hausbeck. 2013a. Age-related resistance to phytophthora fruit rot in 'Dickenson Field' processing pumpkin and 'Golden Delicious' winter squash fruit. Plant Dis. 97:446-552.

Meyer, M.D. and M.K. Hausbeck. 2012. Using cultural practices and cultivar resistance to manage phytophthora crown rot on summer squash. HortScience 47:1080-1084.

Meyer, M.D. and M.K. Hausbeck. 2013b. Using soil-applied fungicides to manage phytophthora crown and root rot on summer squash. Plant Dis. 97:107-112.

Michael, V.N., Y. Fu, and G. Meru. 2019. Inheritance of resistance to phytophthora crown rot in Cucurbita pepo. HortScience 54:1156-1158.

Monroy-Barbosa, A. and P.W. Bosland. 2008. Genetic analysis of phytophthora root rot race-specific resistance in chile pepper. J. Amer. Soc. Hort. Sci. 133:825829.

Oelke, L.M., P.W. Bosland, and R. Steiner. 2003. Differentiation of race specific resistance to phytophthora root rot and foliar blight in Capsicum ann- uum. J. Amer. Soc. Hort. Sci. 128:213218.

Padley, L.D., E.A. Kabelka, P.D. Roberts, and R. French. 2008. Evaluation of Cucurbita pepo accessions for crown rot resistance to isolates of Phytophthora capsici. HortScience 43:1996-1999.

Paris, H.S. 2016. Germplasm enhancement of Cucurbita pepo (pumpkin, squash, gourd: Cucurbitaceae): Progress and challenges. Euphytica 208:415-438.

Paris, H.S. 1996. Summer squash: History, diversity, and distribution. HortTechnology 6:6-13.

Quesada-Ocampo, L.M., L.L. Granke, M.R. Mercier, J. Olsen, and M.K. Hausbeck. 2011. Investigating the genetic structure of Phytophthora capsici populations. Phytopathology 101:10611073.

Tian, D. and M. Babadoost. 2004. Host range of Phytophthora capsici from pumpkin and pathogenicity of isolates. Plant Dis. 88:485-489.

U.S. Department of Agriculture. 2019. Agricultural statistics for 2018. U.S. Dept. Agr., Washington, DC.

U.S. Department of Agriculture. 2020. Web soil survey. I June 2020. <http:// websoilsurvey.sc.egov.usda.gov/>. 